\title{
Contraceptive Knowledge and Contraceptive Attitude of Female Nursing Students of a College
}

\author{
Inn Sook Lee ${ }^{1 *}$ and A Young Cho ${ }^{2}$ \\ ${ }^{1}$ Department of Nursing, Gangdong College \\ ${ }^{2}$ The Heritage Nursing Facility \\ 일개 전문대학 간호과 여학생들의 피임지식과 피임태도 \\ 이인숙 ${ }^{*}$, 조아영 ${ }^{2}$ \\ ${ }^{1}$ 강동대학교 간호과, ${ }^{2}$ 헤리티지너싱홈
}

\begin{abstract}
요 약 본 연구의 목적은 전문대학 간호과 여학생들의 피임지식과 태도를 살펴보고 이 변수들에 대한 영향요인 을 규명하므로써 앞으로 건강교육자로 활동하게 될 간호과 학생들을 위한 좀더 체계적인 피임교육과정 개발에 도 움이 되기 위함이다. 연구대상자는 충청도에 위치한 일개 전문대학 간호과 여학생 254명이었고 연구기간은 2011년 10 월 17 일부터 11 월 11 일까지였다. 대상자의 피임지식은 학년, 성적, 혼전성교 및 혼전동거에 대한 의견에 따라 유 의한 차이가 있었으며 포옹, 키스, 애무 경험 유무에 따라 유의한 차이가 있었다. 대상자의 피임태도는 가정에서의 피임교육 유무에 따라 유의한 차이가 있었고 포옹, 키스, 애무 경험 유무에 따라 유의한 차이가 있었다. 대상자의 피임지식과 태도 간에는 정 상관관계를 나타냈고 피임지식에 대한 영향요인으로는 학년, 혼전동거에 대한 의견, 성 적, 애무경험이었으며 피임태도에 대한 영향요인은 포옹경험과 가정에서의 성교육 유무였다.
\end{abstract}

\begin{abstract}
This study was conducted in order to investigate the contraceptive knowledge, contraceptive attitude and the relationship of the two variables of female nursing students of a college. In this study, 254 female nursing college students by a convenience sample method were studied. Data were collected from October, 17 to November, 11, 2011 and analysed using SPSS/PC Win 12.0 program. Results: The contraceptive knowledge of the subjects significantly differed according to the grade, school record, premarital sexual intercourse, premarital residence, experience of hugging, kissing, and petting. The contraceptive attitude of the subjects significantly differed according to contraceptive education at home, experience of hugging, kissing, and petting. Contraceptive knowledge and contraceptive attitude showed significant positive relationship. The factors influencing contraceptive knowledge were grade, school record, opinion on premarital cohabitation, and the experience of petting. The factors influencing contraceptive attitude were the experience of hugging and contraceptive education at home. College should provide nursing students adequate contraceptive education program according to their general and sexual behavior characteristics.
\end{abstract}

Key Words : Female college student, Contraceptive knowledge, Contraceptive attitude

\section{1. 서론}

\section{1 연구의 필요성}

우리나라의 대학생은 과거 어느 때 보다도 사회적으로
성에 대한 허용성이 높은 시대에 살고 있다. 남녀 대학생 모두가 성 개방 문화에 노출되면서 성 경험의 빈도가 증 가하고 혼전 임신으로 인한 낙태를 경험하기도 한다[1]. 김가영 등[2]의 연구결과에 따르면 남학생의 $65 \%$, 여학

본 논문은 강동대학교 2011학년도 교내 학술연구비 지원에 의하여 연구되었음

${ }^{*}$ Corresponding Author : Inn Sook Lee

Tel: +82-10-9026-7670 email: ilee001@hanmail.net

접수일 12 년 04월 09일 수정일 12년 05월 03일 게재확정일 12 년 07월 12일 
생의 $35.5 \%$ 가 성 경험이 있는 것으로 나타났는데, 이는 1998년 한국성문화연구소가 실시한 '미혼대학생 성 행태 설문조사' 결과 남학생의 $54.5 \%$, 여학생의 $18.4 \%$ 가 '성 교 경험이 있다'로 나타났던 것과 비교하여 남녀 대학생 들의 혼전 성교에 대한 태도가 허용적인 방향으로 변화 하였음을 보여준다. 또한 대학생들의 피임여부를 조사한 결과 '거의 안 한다' $8.9 \%$, '할 때도 있고 안 할 때도 있 다' $44.6 \%$, ‘항상 한다' $46.5 \%$ 로 '항상 한다'는 응답이 약 절반에 불과하였다[3].

피임에 대한 지식은 대학생들이 성행위에서 충동적이 거나 무지로 인해 부적절한 결과를 가져오지 않도록 피 임 사용을 도와주는 인지적 틀로서 피임에 대한 올바른 지식 습득 및 지식의 활용은 원치 않은 임신을 예방할 수 있다[1,4,5,6,7]. 대학생들을 대상으로 한 강희선[8]의 연 구에 따르면 응급피임약 사용에 대한 태도를 구성하는 영역 중 하나로서 건강염려 요인이 있는데, 이는 응급피 임약에 대한 정확한 지식이 없는 상태에서 나온 결과라 고 하였다. 또한 피임을 하지 않는 대학생들에게 피임을 하지 않은 이유에 대해 질문한 결과, 피임방법을 모른다 는 응답이 $20 \%$ 정도였고[1] 청소년을 대상으로 한 Wang 등[6]의 연구에서는 청소년의 임신과 관련된 6가지 요인 중 하나로 낮은 피임지식을 들었다. 이러한 결과를 볼 때, 피임에 대한 정확한 지식을 전달하는 것은 매우 중요한 일이라 하겠다.

피임에 대한 태도는 개인이 임신예방을 위해 피임사용 에 대해 내리는 긍정적 또는 부정적인 평가의 정도를 의 미한다. 즉, 피임에 대한 태도는 한 개인이 피임사용에 대 해 갖고 있는 호불호(好不好)의 정도를 보여주는 것으로 대학생들의 성행동을 결정하는데 있어 구체적인 행동적 지침으로 작용할 수 있다. 피임지식이 피임방법이나 결과 등에 대한 정보적인 측면이라면 피임태도는 피임에 대한 인지적 측면뿐 아니라 평가적 측면까지 포함하는 보다 포괄적인 개념이다[1]. 따라서 피임에 대한 태도가 긍정 적일수록 피임에 대해 공동책임을 느끼며 이를 위해 성 파트너와 효율적인 의사소통을 하고 피임행위를 실천하 려는 책임감을 갖게 된다[9].

현대사회는 젊은 세대들의 가치관 변화와 독립된 경제 력을 가진 미혼남녀의 숫자가 증가하고 그들이 폭넓은 대인관계를 경험하면서 자유로운 성관계의 기회가 예전 보다 더 많아지게 된 시기이다[10]. 따라서 이들 미혼남 녀들에게 올바른 피임지식과 긍정적인 피임태도를 심어 주는 일은 건강교육자로서 매우 중요한 역할이라 할 수 있다. 간호사는 이러한 건강교육을 담당할 수 있는 보건 의료인력 중 매우 중요한 위치에 있는데, 학교에서는 보 건교사로, 산업장에서는 건강관리자로, 보건소에서는 다
양한 클리닉에서 여성건강을 위해 근무하고 있다.

이러한 점을 고려할 때, 졸업 후 사회에 나아가 다양한 보건의료 현장에서 활동하게 될 간호과 여학생들의 피임 지식과 피임태도를 파악해보는 것은 매우 의미있는 일이 라 생각한다. 그러나 이제까지 피임에 관련된 대부분의 연구가 중·고등학생[3,11,12,13], 대학생[1,2,7,8,14,15], 미혼남녀[10], 기혼여성[16,17]을 대상으로 이루어졌을 뿐 건강교육을 담당하게 될 간호과 여학생들을 대상으로 수행된 경우는 없었다. 이에 본 연구에서는 간호과 여학 생들의 피임지식과 태도를 살펴보고 이들 변수에 영향을 미치는 요인들을 파악하므로써 간호과 여학생들에게 좀 더 효과적인 피임교육을 제공하는 데 도움이 되고자 한다.

\section{2 연구의 목적}

본 연구는 전문대학 간호과 여학생들의 피임지식과 태 도에 대하여 파악하고자 하며 구체적인 목적은 다음과 같다.

1) 대상자의 일반적 특성과 성행위 경험 여부에 따른 피임지식의 차이를 파악한다.

2) 대상자의 일반적 특성과 성행위 경험 여부에 따른 피임태도의 차이를 파악한다.

3) 대상자의 피임지식과 태도 간의 상관관계를 파악한 다.

4) 대상자의 피임지식과 태도에 영향을 미치는 요인을 파악한다.

\section{2. 연구방법}

\section{1 연구설계}

본 연구는 전문대학 간호과 여학생들의 피임지식과 태 도를 살펴보고 두 변수 간의 상관관계를 파악하기 위한 단면적 조사연구이다.

\section{2 연구대상 및 연구기간}

본 연구의 대상자는 충청도에 위치한 일개 전문대학 간호과 여학생 254명이었으며 자료수집기간은 2011년 10 월 17 일부터 11 월 11 일까지였다. 총 300 부를 배부한 결과 258 부를 회수하였고 $(86.0 \%)$ 이 중 응답이 불충분한 4 부를 제외한 254 부 $(84.7 \%)$ 를 분석에 사용하였다. $\mathrm{G}^{*}$ power3 program[18]을 이용하여 power analysis를 시 행한 결과 본 연구의 대상자수 254 명은 유의수준 0.05 , 효과크기 0.25 에서 power가 0.90 인 것으로 나타났다. 


\section{3 연구도구}

\subsection{1 피임지식}

피임지식을 측정하기 위하여 김미종[16]이 제작한 피 임지식 측정도구를 사용하였다. 이 도구는 총 15 개의 문 항으로 구성되어 있으며 피임의 원리, 장.단점, 사용방법 등 피임에 관한 정보를 진술한 문항들로 '그렇다', '아니 다', '모르겠다' 로 표시하도록 되어있다. 정답은 1점, 오 답은 0 점을 주어 피임지식 점수의 범위는 0 점에서 15 점 이었다. 도구의 신뢰도는 김미종(2001)의 연구에서 Cronbach's $a=.60$ 이었고 본 연구에서는 .76 이었다.

\subsection{2 피임태도}

피임태도를 측정하기 위해 김미종[16]이 수정 보완하 여 개발한 도구를 사용하였다. 도구의 내용으로는 '피임 을 하는 것은 바람직한 일이다'를 포함하여 총 6개 문항 5점 척도로 '매우 그렇다(5점)'에서 '전혀 그렇지 않다(1 점)'로 구성되었으며 피임태도의 점수 범위는 6점에서 30 점이었다. 피임태도 점수가 높을수록 피임행위에 대한 태 도가 긍정적인 것을 의미한다. 도구의 신뢰도는 김미종 (2001)의 연구에서 Cronbach's $a=.83$ 이었고 본 연구에서 는 .77이었다.

\section{4 연구절차}

대상자들에게 본 연구의 목적과 설문지의 작성방법을 설명한 후 연구에 참여하기를 허락한 학생들에 대하여 설문지를 배포하였다. 또한 설문지 맨 앞장에 서면동의서 를 첨부하여 본 연구에의 참여여부에 따라 어떠한 불이 익도 없음을 재차 강조하였다. 설문지 작성 시간은 약 15 분 정도였으며 작성이 완료되는 즉시 그 자리에서 회수 하였다. 배포한 설문지 270 부 가운데 260 부(96.3\%)가 회 수되었으며 이 중 기입한 내용이 불성실한 6 부를 제외한 254부(94.1\%)를 분석에 사용하였다.

\section{5 자료분석 방법}

자료분석은 SPSS 12.0 프로그램을 이용하였다. 대상 자의 일반적 특성과 성행위 경험에 대해서는 기술통계를 이용하여 실수와 백분률을 산출하였다. 대상자의 인구학 적 특성에 따른 피임지식과 태도의 차이는 t-test와 ANOVA를 사용하였으며 사후검정을 위해 Scheffe 검정 을 실시하였다. 대상자의 피임지식과 태도 간의 상관관계 는 피어슨 상관계수(Pearson's correlation coefficient)을 이용하였고 피임지식과 태도에 영향을 미치는 요인을 파 악하기 위해 다중회귀분석(multiple regression analysis)을 실시하였다.

\section{3. 연구결과}

\section{1 대상자의 일반적 특성}

학년에 있어 1학년이 $34.6 \%$, 2학년 $33.1 \%$, 3학년이 $32.3 \%$ 이었다. 종교를 갖고 있는 경우가 $50.8 \%$, 성적은 중간인 경우가 $59.4 \%$ 이었다. 음주여부에 있어 술을 마시 지 않는다는 응답이 $69.7 \%$, 흡연여부에 있어 흡연을 하 지 않는다는 응답이 $95.7 \%$ 이었다. 거주형태에 있어서는 가족들과 함께 거주한다는 응답이 $83.1 \%$ 엿고 부모님의 학력은 각각 고졸이 $59.4 \%, 66.5 \%$ 이었다. 가정에서 피임 교육을 받은 경험이 있다는 응답이 $23.6 \%$ 였고 학교에서 피임교육을 받은 경험이 있다는 응답은 $93.7 \%$ 이었다. 이 성교제에 대한 경험이 있는 경우는 $73.6 \%$ 였고 혼전성교 를 찬성한다는 응답이 $33.9 \%$, 반대한다는 응답이 $31.9 \%$ 이었다. 혼전동거에 대해서는 찬성한다가 $17.7 \%$, 반대한 다는 $65.7 \%$ 이었다<Table 1 .

\section{2 대상자의 성행위 경험 특성}

이성과의 성행위 경험은 이성과 손을 잡아본 경험이 $95.3 \%$, 포옹경험 $86.6 \%$, 키스경험 $68.9 \%$, 애무경험이 $44.9 \%$ 인 것으로 나타났다<Table 2>.

\section{3 대상자의 일반적 특성에 따른 피임지식의 차이}

대상자의 피임지식은 15 점 만점에 평균 9.50 점(SD $2.79,100$ 점 만점에 63.31 점)이었으며 일반적 특성에 따 른 피임지식은 학년, 성적, 혼전성교 및 혼전동거에 대한 의견에 따라 유의한 차이를 나타냈다<Table 1>. 학년에 있어 2학년의 피임지식이 15 점 만점에 10.52점으로 가장 높았고 다음으로 3 학년, 1 학년의 순이었다 $(\mathrm{F}=24.732$, $\mathrm{p}=.000$ ). 이에 대한 사후분석 결과, 2 학년이 1 학년에 비해 피임지식이 유의하게 높은 것으로 나타났다. 성적에 있어 서는 상위 집단의 피임지식이 10.95 점으로 가장 높았고 다음으로 중간, 하위의 순으로 나타났다 $(\mathrm{F}=9.167$, $\mathrm{p}=.000$ ), 이에 대한 사후분석 결과, 성적이 상위인 집단이 하위인 집단에 비해 피임지식이 유의하게 높은 것으로 나타났다. 혼전성교에 대한 의견에 있어 혼전성교에 찬성 한다고 응답한 집단의 피임지식이 9.98점으로 가장 높았 고 그 다음으로 반대한다, 잘 모르겠다의 순인 것으로 나 타났다 $(\mathrm{F}=3.262, \mathrm{p}=.040)$.

이에 대한 사후분석 결과, 혼전성교에 찬성하다는 집 단이 잘 모르겠다고 응답한 집단에 비해 피임지식이 유 의하게 높은 것으로 나타났다. 혼전동거에 대한 의견에 있어 혼전동거에 찬성한다고 응답한 집단의 피임지식이 
[표 1] 일반적 특성에 따른 피임지식의 차이

[Table 1] Difference of contraceptive knowledge according to general characteristics

$(\mathrm{N}=254)$

\begin{tabular}{|c|c|c|c|c|c|c|}
\hline Characteristics & Categories & $\mathrm{n}(\%)$ & mean $\pm \mathrm{SD}$ & $\mathrm{t}$ or $\mathrm{F}$ & $p$ & Scheffe \\
\hline Grade & $\begin{array}{l}\text { Freshman }^{\mathrm{a}} \\
\text { Sophomore }^{\mathrm{b}} \\
\text { Junior }^{\mathrm{b}}\end{array}$ & $\begin{array}{l}88(34.6) \\
84(33.1) \\
82(32.3)\end{array}$ & $\begin{array}{r}7.97 \pm 2.59 \\
10.52 \pm 2.38 \\
10.09 \pm 2.69\end{array}$ & 24.732 & .000 & $\mathrm{a}<\mathrm{b}$ \\
\hline Religion & $\begin{array}{c}\text { Have } \\
\text { Don't have }\end{array}$ & $\begin{array}{l}129(50.8) \\
125(49.2)\end{array}$ & $\begin{array}{l}9.78 \pm 2.57 \\
9.21 \pm 2.98\end{array}$ & 1.627 & .105 & \\
\hline School record & $\begin{array}{l}\text { High }^{\mathrm{a}} \\
\text { Middle }^{\mathrm{b}} \\
\text { Low }^{\mathrm{b}}\end{array}$ & $\begin{array}{r}41(16.1) \\
151(59.5) \\
62(24.4) \\
\end{array}$ & $\begin{array}{r}10.95 \pm 2.04 \\
9.46 \pm 2.81 \\
8.63 \pm 2.80 \\
\end{array}$ & 9.167 & .000 & $a>b$ \\
\hline Drinking & $\begin{array}{l}\text { Yes } \\
\text { No }\end{array}$ & $\begin{array}{r}77(30.3) \\
177(69.7) \\
\end{array}$ & $\begin{array}{l}9.70 \pm 2.80 \\
9.41 \pm 2.78\end{array}$ & .774 & .440 & \\
\hline Smoking & $\begin{array}{l}\text { Yes } \\
\text { No }\end{array}$ & $\begin{array}{r}11(4.3) \\
243(95.7) \\
\end{array}$ & $\begin{array}{l}9.73 \pm 3.17 \\
9.49 \pm 2.77\end{array}$ & .281 & .779 & \\
\hline Residence & $\begin{array}{l}\text { My house } \\
\text { etc. }\end{array}$ & $\begin{array}{r}211(83.1) \\
43(16.9) \\
\end{array}$ & $\begin{array}{l}9.59 \pm 2.82 \\
9.02 \pm 2.57\end{array}$ & 1.222 & .223 & \\
\hline Father's education & $\begin{array}{c}\leq \text { Middle school } \\
\text { High school } \\
\text { College } \leq\end{array}$ & $\begin{array}{r}37(14.6) \\
151(59.4) \\
66(26.0) \\
\end{array}$ & $\begin{array}{l}9.65 \pm 2.77 \\
9.34 \pm 2.52 \\
9.77 \pm 3.35 \\
\end{array}$ & .623 & .537 & \\
\hline Mother's education & $\begin{array}{c}\leq \text { Middle school } \\
\text { High school } \\
\text { College } \leq\end{array}$ & $\begin{array}{r}45(17.7) \\
169(66.5) \\
40(15.8)\end{array}$ & $\begin{array}{r}9.71 \pm 2.52 \\
9.28 \pm 2.70 \\
10.18 \pm 3.32\end{array}$ & 1.852 & .159 & \\
\hline $\begin{array}{c}\text { Contraceptive education at } \\
\text { home }\end{array}$ & $\begin{array}{c}\text { Have } \\
\text { Don't have }\end{array}$ & $\begin{array}{r}60(23.6) \\
194(76.4) \\
\end{array}$ & $\begin{array}{r}10.00 \pm 2.50 \\
9.34 \pm 2.86 \\
\end{array}$ & 1.608 & .109 & \\
\hline $\begin{array}{c}\text { Contraceptive } \\
\text { education at school }\end{array}$ & $\begin{array}{c}\text { Have } \\
\text { Don't have }\end{array}$ & $\begin{array}{r}238(93.7) \\
16(6.3) \\
\end{array}$ & $\begin{array}{l}9.57 \pm 2.75 \\
8.44 \pm 3.18\end{array}$ & 1.575 & .117 & \\
\hline $\begin{array}{l}\text { Acquaintance of the } \\
\text { opposite sex }\end{array}$ & $\begin{array}{c}\text { Have } \\
\text { Don't have }\end{array}$ & $\begin{array}{r}187(73.6) \\
67(26.4) \\
\end{array}$ & $\begin{array}{l}9.68 \pm 2.61 \\
8.99 \pm 3.19 \\
\end{array}$ & 1.757 & .080 & \\
\hline Premarital coitus & $\begin{array}{c}\text { Agree }^{\mathrm{a}} \\
\text { Disagree } \\
\text { Don't know }^{\mathrm{b}} \\
\end{array}$ & $\begin{array}{l}86(33.9) \\
81(31.9) \\
87(34.2) \\
\end{array}$ & $\begin{array}{l}9.98 \pm 2.41 \\
9.61 \pm 2.82 \\
8.92 \pm 3.02 \\
\end{array}$ & 3.262 & .040 & $a>b$ \\
\hline Premarital cohabitation & $\begin{array}{c}\text { Agree }^{\mathrm{a}} \\
\text { Disagree } \\
\text { Don't know }^{\mathrm{b}}\end{array}$ & $\begin{array}{r}45(17.7) \\
167(65.8) \\
42(16.5)\end{array}$ & $\begin{array}{r}10.09 \pm 2.24 \\
9.60 \pm 2.79 \\
8.43 \pm 3.07 \\
\end{array}$ & 4.341 & .014 & $a>b$ \\
\hline total & & & $9.50 \pm 2.79$ & & & \\
\hline
\end{tabular}

10.09점으로 가장 높았고 그 다음으로 반대한다, 잘 모르 겠다의 순인 것으로 나타났다 $(\mathrm{F}=4.341, \mathrm{p}=.014)$.

이에 대한 사후분석 결과, 혼전동거에 찬성한다는 집 단이 모르겠다고 응답한 집단에 비해 피임지식이 유의하 게 높은 것으로 나타났다.

\section{4 대상자의 성행위 경험에 따른 피임지식의 차이}

대상자의 이성과의 성행위 경험에 따른 피임지식은 이 성과의 포옹 $(\mathrm{t}=-2.122, \mathrm{p}=.040), \quad$ 키스 $(\mathrm{t}=-2.527, \mathrm{p}=.013)$, 애무 $(\mathrm{t}=-3.776, \mathrm{p}=.000)$ 경험이 있는 집단이 경험이 없는 집단에 비해 피임에 대한 지식이 유의하게 높았다<Table $2>$.
[표 2] 성행위 경험에 따른 피임지식의 차이

[Table 2] Difference of contraceptive knowledge according to sexual behavior

$(\mathrm{N}=254)$

\begin{tabular}{|c|c|r|r|c|c|}
\hline Characteristics & Categories & $\mathrm{n}(\%)$ & $\operatorname{mean} \pm \mathrm{SD}$ & $\mathrm{t}$ & $p$ \\
\hline $\begin{array}{c}\text { Clasping } \\
\text { hands }\end{array}$ & Yes & $242(95.3)$ & $9.60 \pm 2.67$ & -1.682 & .120 \\
\hline \multirow{2}{*}{ No } & $12(4.7)$ & $7.50 \pm 4.28$ & & \\
\hline \multirow{2}{*}{ Kisging } & Yes & $220(86.6)$ & $9.67 \pm 2.65$ & -2.122 & .040 \\
& No & $34(13.4)$ & $8.38 \pm 3.38$ & & \\
\hline \multirow{2}{*}{ Petting } & Yes & $175(68.9)$ & $9.82 \pm 2.52$ & -2.527 & .013 \\
& No & $79(31.1)$ & $8.79 \pm 3.21$ & & \\
\hline & No & $114((44.9)$ & $10.19 \pm 2.35$ & -3.776 & .000 \\
\hline
\end{tabular}


[표 3] 성행위 경험에 따른 피임태도의 차이

[Table 3] Difference of contraceptive attitude according to sexual behavior

$(\mathrm{N}=254)$

\begin{tabular}{|c|c|c|c|c|c|}
\hline Characteristics & Categories & $\mathrm{n}(\%)$ & mean \pm SD & $\mathrm{t}$ & $\mathrm{p}$ \\
\hline \multirow{2}{*}{$\begin{array}{c}\text { Clasping } \\
\text { hands }\end{array}$} & Yes & $242(95.3)$ & $27.48 \pm 2.84$ & \multirow{2}{*}{-1.935} & \multirow{2}{*}{.054} \\
\hline & No & $12(4.7)$ & $25.83 \pm 3.66$ & & \\
\hline \multirow{2}{*}{ Hugging } & Yes & $220(86.6)$ & $27.58 \pm 2.84$ & \multirow{2}{*}{-2.555} & \multirow{2}{*}{.011} \\
\hline & No & $34(13.4)$ & $26.24 \pm 2.98$ & & \\
\hline \multirow{2}{*}{ Kissing } & Yes & $175(68.9)$ & $27.68 \pm 2.73$ & \multirow{2}{*}{-2.304} & \multirow{2}{*}{.022} \\
\hline & No & $79(31.1)$ & $26.79 \pm 3.16$ & & \\
\hline \multirow{2}{*}{ Petting } & Yes & $114((44.9)$ & $27.90 \pm 2.44$ & \multirow{2}{*}{-2.543} & \multirow{2}{*}{.012} \\
\hline & No & $140(55.1)$ & $27.00 \pm 3.17$ & & \\
\hline
\end{tabular}

\section{5 대상자의 일반적 특성에 따른 피임태도의 차이}

대상자의 피임태도는 30점 만점에 27.40점이었으며 (SD 2.89, 100점 만점에 91.34점) 일반적 특성에 따른 피 임태도는 가정에서의 피임교육 경험 여부에 따라 유의한 차이를 나타냈다<Table 4>. 가정에서 피임교육을 받은 경험이 있는 집단의 피임태도가 30점 만점에 28.15점으 로 가정에서 피임교육을 받은 경험이 없는 집단의 27.17 점보다 유의하게 높았다 $(\mathrm{t}=2.608, \mathrm{p}=.010)$.

[표 4] 일반적 특성에 따른 피임에 대한 태도의 차이

[Table 4] Difference of contraceptive attitude according to general characteristics

$(\mathrm{N}=254)$

\begin{tabular}{|c|c|c|c|c|c|}
\hline Characteristics & Category & $\mathrm{n}(\%)$ & mean \pm SD & $\mathrm{t}$ or $\mathrm{F}$ & $p$ \\
\hline Grade & $\begin{array}{l}\text { Freshman } \\
\text { Sophomore } \\
\text { Junior }\end{array}$ & $\begin{array}{l}88(34.6) \\
84(33.1) \\
82(32.3)\end{array}$ & $\begin{array}{l}26.30 \pm 3.49 \\
28.07 \pm 2.48 \\
27.90 \pm 2.16\end{array}$ & .089 & .117 \\
\hline Religion & $\begin{array}{c}\text { Have } \\
\text { Don't have }\end{array}$ & $\begin{array}{l}129(50.8) \\
125(49.2)\end{array}$ & $\begin{array}{l}27.50 \pm 2.75 \\
27.30 \pm 3.04\end{array}$ & .529 & .597 \\
\hline School record & $\begin{array}{l}\text { High }^{\mathrm{a}} \\
\text { Middle }^{\mathrm{b}} \\
\text { Low }^{\mathrm{c}}\end{array}$ & $\begin{array}{r}41(16.1) \\
151(59.5) \\
62(24.4)\end{array}$ & $\begin{array}{l}27.33 \pm 2.84 \\
27.39 \pm 2.92 \\
27.48 \pm 2.91\end{array}$ & .043 & .958 \\
\hline Drinking & $\begin{array}{l}\text { Yes } \\
\text { No }\end{array}$ & $\begin{array}{r}77(30.3) \\
177(69.7)\end{array}$ & $\begin{array}{l}27.16 \pm 3.10 \\
27.51 \pm 2.80\end{array}$ & -.893 & .373 \\
\hline Smoking & $\begin{array}{l}\text { Yes } \\
\text { No }\end{array}$ & $\begin{array}{r}11(4.3) \\
243(95.7)\end{array}$ & $\begin{array}{l}27.09 \pm 3.17 \\
27.42 \pm 2.77\end{array}$ & -.364 & .716 \\
\hline Residence & $\begin{array}{l}\text { My house } \\
\text { etc. }\end{array}$ & $\begin{array}{r}211(83.1) \\
43(16.9)\end{array}$ & $\begin{array}{l}27.46 \pm 2.80 \\
27.12 \pm 3.34\end{array}$ & .709 & .479 \\
\hline Father's education & $\begin{array}{c}\leq \text { Middle school } \\
\text { High school } \\
\text { College } \leq\end{array}$ & $\begin{array}{r}37(14.6) \\
151(59.4) \\
66(26.0)\end{array}$ & $\begin{array}{l}27.51 \pm 3.00 \\
27.53 \pm 2.81 \\
27.05 \pm 3.03\end{array}$ & .675 & .510 \\
\hline Mother's education & $\begin{array}{c}\leq \text { Middle school } \\
\text { High school } \\
\text { College } \leq\end{array}$ & $\begin{array}{r}45(17.7) \\
169(66.5) \\
40(15.8)\end{array}$ & $\begin{array}{l}27.33 \pm 3.01 \\
27.41 \pm 2.87 \\
27.45 \pm 2.93\end{array}$ & .018 & .982 \\
\hline $\begin{array}{c}\text { Contraceptive education at } \\
\text { home }\end{array}$ & $\begin{array}{c}\text { Have } \\
\text { Don't have }\end{array}$ & $\begin{array}{r}60(23.6) \\
194(76.4)\end{array}$ & $\begin{array}{l}28.15 \pm 2.39 \\
27.17 \pm 3.00\end{array}$ & 2.608 & .010 \\
\hline $\begin{array}{c}\text { Contraceptive education at } \\
\text { school }\end{array}$ & $\begin{array}{c}\text { Have } \\
\text { Don't have }\end{array}$ & $\begin{array}{r}238(93.7) \\
16(6.3)\end{array}$ & $\begin{array}{l}27.41 \pm 2.88 \\
27.25 \pm 3.04\end{array}$ & .216 & .829 \\
\hline $\begin{array}{l}\text { Acquaintance of } \\
\text { the opposite sex }\end{array}$ & $\begin{array}{c}\text { Have } \\
\text { Don't have }\end{array}$ & $\begin{array}{r}187(73.6) \\
67(26.4)\end{array}$ & $\begin{array}{l}27.58 \pm 2.85 \\
26.91 \pm 2.97\end{array}$ & 1.626 & .105 \\
\hline Premarital coitus & $\begin{array}{c}\text { Agree } \\
\text { Disagree } \\
\text { Don't know }\end{array}$ & $\begin{array}{l}86(33.9) \\
81(31.9) \\
87(34.2)\end{array}$ & $\begin{array}{l}27.90 \pm 2.37 \\
26.86 \pm 3.16 \\
27.41 \pm 3.04\end{array}$ & 2.689 & .070 \\
\hline Premarital cohabitation & $\begin{array}{c}\text { Agree } \\
\text { Disagree } \\
\text { Don't know }\end{array}$ & $\begin{array}{r}45(17.7) \\
167(65.8) \\
42(16.5)\end{array}$ & $\begin{array}{l}27.82 \pm 2.72 \\
27.38 \pm 2.90 \\
27.02 \pm 3.03\end{array}$ & .837 & .434 \\
\hline total & & & $27.40 \pm 2.89$ & & \\
\hline
\end{tabular}




\section{6 대상자의 성행위 경험에 따른 피임태도의 차이}

이성과의 성행위 경험에 따른 피임태도는 이성과의 포 옹 $(\mathrm{t}=-2.555, \quad \mathrm{p}=.011), \quad$ 키스 $(\mathrm{t}=-2.304, \quad \mathrm{p}=.022)$, 애무 $(\mathrm{t}=-2.543, \mathrm{p}=.012)$ 경험이 있는 집단이 그렇지 않은 집단 에 비해 피임태도가 유의하게 긍정적인 것으로 나타났다.

\section{7 대상자의 피임지식과 태도 간의 상관관계}

피임지식과 태도는 정 상관관계에 있어 피임지식이 높 을수록 피임태도가 긍정적인 것으로 나타났다 $(\mathrm{r}=.205$, $\mathrm{p}=.001)$.

[표 5] 피임지식과 태도 간의 상관관계

[Table 5] Correlation among contraceptive knowledge and attitude

\begin{tabular}{|c|c|c|}
\hline \multirow{2}{*}{ Variables } & $\begin{array}{c}\text { Contraceptive } \\
\text { knowledge }\end{array}$ & $\begin{array}{c}\text { Contraceptive } \\
\text { attitude }\end{array}$ \\
\cline { 2 - 3 } & $\mathrm{r}(p)$ & $\mathrm{r}(p)$ \\
\hline $\begin{array}{c}\text { Contraceptive } \\
\text { knowledge }\end{array}$ & 1 & $.205(.001)$ \\
\hline
\end{tabular}

\section{8 대상자의 피임지식에 영향을 미치는 요인}

피임지식에 영향을 미치는 변수로 학년, 성적, 혼전성 경험 및 혼전동거에 대한 의견, 포옹, 키스, 애무경험을 독립변수로 선택하여 투입한 결과, 학년, 성적, 애무경험 이 피임지식에 영향을 미치는 요인으로 나타났으며 이 요인들의 설명력은 $22.5 \%$ 이었다<Table $6>$.

\section{9 대상자의 피임태도에 영향을 미치는 요인}

피임태도에 영향을 미치는 변수로 가정에서의 성교육 유무, 포옹, 키스, 애무경험을 독립변수로 선택하여 투입 한 결과, 포옹경험, 가정에서의 성교육 유무가 피임태도 에 영향을 미치는 요인으로 나타났으며 이 요인들의 설 명력은 $4.3 \%$ 이었다<Table $7>$.

\section{4. 논의}

본 연구결과 대상자의 피임지식은 15 점 만점에 평균 9.50점(100점 만점, 63.31점)이었다. 본 연구와 동일한 도 구를 사용하여 측정했던 김가영 등[2]의 연구에서의 7.33 점, 송주은, 채현주[7]의 연구에서의 7.6점, 최정현 등[1] 의 연구에서의 6.1점과 비교해 볼 때, 본 연구 대상자의 피임지식 점수가 더 높았다. 이는 간호과 학생들의 경우 기초간호과학을 통해 생식기계에 대한 해부생리학적 지 식을 익히고 전공교과목인 모성간호학과 지역사회간호학 등에서 피임의 원리와 방법, 장단점에 대한 지식을 습득 하게 되어 피임지식이 높게 나타난 것으로 사료된다. 일 반적 특성에 따른 피임지식은 학년, 성적, 혼전성교, 혼전 동거에 대한 의견에 있어서 유의한 차이를 보였다. 학년 에 있어 2 학년의 피임지식이 15 점 만점에 10.524 점으로 가장 높았고 다음으로 3 학년, 1 학년의 순이었으며 이에 대한 사후분석 결과, 2학년이 1학년에 비해 피임지식이 유의하게 높았다. 1학년 학생들의 경우 해부학과 생리학 을 통해 생식기계의 해부생리를 학습하지만 피임의 원리

[표 6] 피임지식에 영향을 미치는 요인

[Table 6] Factors influencing contraceptive knowledge

\begin{tabular}{|c|c|c|c|c|c|c|c|c|c|}
\hline Variables & B & SD & $\mathrm{t}$ & $p$ & $\mathrm{R}$ & $\mathrm{R}^{2}$ & Adj. $R^{2}$ & $\mathrm{~F}$ & $p$ \\
\hline Grade & 2.117 & .335 & 6.322 & .000 & \multirow{4}{*}{.474} & \multirow{4}{*}{.225} & \multirow{4}{*}{.212} & \multirow{4}{*}{18.057} & \multirow{4}{*}{.000} \\
\hline Premarital cohabitation & 1.067 & .421 & 2.534 & .012 & & & & & \\
\hline School record & .912 & .364 & 2.505 & .013 & & & & & \\
\hline Petting & -.749 & .321 & -2.337 & .020 & & & & & \\
\hline
\end{tabular}

[표 7] 피임태도에 영향을 미치는 요인

[Table 7] Factors influencing contraceptive attitude

\begin{tabular}{|c|c|c|c|c|c|c|c|c|c|}
\hline Variables & $\mathrm{B}$ & $\mathrm{SD}$ & $\mathrm{t}$ & $p$ & $\mathrm{R}$ & $\mathrm{R}^{2}$ & Adj. $\mathrm{R}^{2}$ & $\mathrm{~F}$ & $p$ \\
\hline Hugging & -1.254 & .525 & -2.388 & .018 & & .043 & & & \\
\hline $\begin{array}{c}\text { Contraceptive education } \\
\text { at home }\end{array}$ & .897 & .421 & 2.130 & .034 & .206 & .035 & 5.578 & .004 \\
\hline
\end{tabular}


에 대해서는 모성간호학이 시작되는 2 학년에서 학습하게 되므로 2 학년이 1 학년의 피임지식보다 높게 나타난 것으 로 생각한다. 성적이 상위인 집단의 피임지식이 10.95점 으로 가장 높았고 다음으로 중간, 하위집단의 순이었다. 이에 대한 사후분석 결과, 성적이 상위인 집단이 하위인 집단에 비해 피임지식이 유의하게 높았다. 이는 인문계와 실업계 여고생을 대상으로 한 이인숙과 조주연[12]의 연 구결과와 일치하고 있다. 학생들 각자가 선호하는 교과목 에 차이가 있을 수 있으나 상위권 학생들의 경우 대체로 모든 교과목에 열의를 갖고 학업에 임하게 되므로 상위 권 집단에서 피임지식이 가장 높게 나타난 것으로 사료 된다. 혼전성교에 대한 의견에 있어 혼전성교를 찬성하는 집단의 피임지식이 9.98점으로 가장 높았고 다음으로 반 대한다, 잘 모르겠다의 순이었다. 이에 대한 사후분석 결 과, 혼전성교를 찬성하는 집단이 잘 모르겠다고 응답한 집단에 비해 피임지식이 유의하게 높았다. 이는 성관계 경험군이 비경험군에 비해 피임에 대한 객관적 지식이 높았던 송주은과 채현주[7]의 연구결과와 어느 정도 맥락 을 같이 하고 있다. 혼전성교에 대한 태도가 개방적일수 록 폐쇄적인 집단에 비해 성교의 가능성이 높을 것으로 사료되며 성교로 인해 임신을 초래할 가능성이 있는 만 큼 피임지식을 보다 적극적으로 구하게 되어 나타난 결 과로 사료된다. 이러한 결과를 볼 때, 성생활을 하는 여성 에게 있어서 피임을 지속적으로 하지 않는 것은 의도하 지 않았던 임신의 위험성을 갖게 하고 이는 여성건강에 큰 저해요인이 될 수 있으므로[17] 피임지식은 가임기 여 성이라면 누구나 갖추어야 할 필수적인 지식이라 하겠다. 혼전동거에 대한 의견에 있어서는 혼전동거에 찬성한 집 단의 피임지식이 10.09 점으로 가장 높았고 다음으로 반 대한다, 잘 모르겠다의 순이었으며 이에 대한 사후분석 결과, 혼전동거에 찬성한다는 집단이 잘 모르겠다고 응답 한 집단에 비해 피임지식이 유의하게 높았다. 이는 혼전 동거를 찬성하는 것은 앞서 언급한 혼전성교까지 수용할 의사가 있음을 의미하므로 성교로 인해 초래할 수 있는 임신을 해결하거나 이를 예방하는 차원에서 피임지식을 구하게 되어 나타난 결과로 본다. 이성과의 성행위 경험 에 따른 피임지식의 차이를 살펴본 결과, 포옹, 키스, 애 무 경험이 있는 집단이 그렇지 않은 집단에 비해 피임지 식이 유의하게 높았다. 이러한 결과는 허명행 등(2007)의 연구에서 성교 유경험자의 피임지식이 무경험자의 지식 보다 유의하게 높았던 결과와 일치하고 있다. 남자 고등 학생을 대상으로 한 조주연과 이인숙[13]의 연구에서도 이성교제 경험이 있는 집단의 피임지식이 더 높은 것으 로 나타났다. 이성교제를 하는 집단의 경우 이성 간의 만 남을 통해 혼전성교까지 경험하게 될 가능성이 높으므로
성교에 의한 임신 가능성을 보다 실질적인 위협으로 인 식하게 되며 이로 인해 스스로 피임지식을 찾기 위한 노 력을 하기 때문이라 추론해 볼 수 있다[7]. 이러한 결과를 볼 때, 피임지식이 체계적인 성교육을 통해 향상될 수 있 으나 개인적인 성적경험을 통해서도 습득되는 측면이 있 음을 알 수 있겠다. Campo 등[4]은 낮은 피임지식, 음주, 성에 대한 계획 부족, 임신 가능성에 대한 잘못된 인식, 피임법 사용에 대한 망각, 피임법의 부작용 및 비용에 대 한 걱정이 피임법 사용에 부정적인 영향을 미친다고 하 였다. 또한 여자 치과대학원생을 대상으로 한 Dinas 등[5] 에 의하면 학생들 중 $20.5 \%$ 가 경구용 피임약이 암 발생 위험을 증가시킨다고 하였고 $36.4 \%$ 는 경구용 피임제와 암 발생 위험 간의 관련성을 모른다고 하였다. 이렇듯 피 임지식의 부족은 피임을 실천하는 데 있어 커다란 장애 물로 작용하고 있음을 알 수 있다. 대학생 시기는 고교시 절과는 달리 이성과 만날 기회가 증가하고 음주상태에서 성관계에 노출될 가능성도 높아진다. 즉, 본의 아니게 성 관계를 하게 되고 그 결과로서 원치 않은 임신을 할 가능 성이 증가하는 것이다. 이러한 맥락에서 보면 미국 초기 성인기의 성교육 요구도에 대한 Von, Kovar, Brown 및 Armbruster[19]의 연구에서 대학생들이 원하는 이상적인 성교육 프로그램은 피임에 대하여 “겁을 주는 교육"이 아닌 "알아야 할 것들을 사실적이고 정확하게 그리고 편 안하게" 알려주는 것[15]이라는 주장에 충분히 공감할 수 있다.

대상자의 피임태도는 30 점 만점에 27.40 점이었다. 이 는 대학생을 대상으로 한 허명행 등[15]의 연구에서 60 점 만점에 40.93점, 최정현 등[1]의 연구에서 5 점 만점에 3.81점(100점 만점에 76.20점)과 비교해 볼 때, 매우 긍정 적인 피임태도를 나타냈다. 이와 같이 선행연구에 비해 긍정적인 피임태도를 나타낸 것은 피임태도에 대한 측정 도구가 계획된 출산의 장점과 피임의 필요성에 관하여 구성되었기 때문에 교과과정을 통해 피임의 원리와 인공 중절술의 부작용을 배운 간호과 여학생들의 입장에서는 피임에 대해 좀더 긍정적으로 답변했을 가능성이 높다고 생각한다. 일반적 특성에 따른 피임태도를 살펴본 결과, 가정에서 피임교육을 받은 집단의 피임태도가 30점 만점 에 28.15점으로 피임교육을 받지 않은 집단의 27.17점보 다 유의하게 높았다. 여고생을 대상으로 한 이인숙과 조 주연[12]의 연구에서는 가정에서 피임교육을 받은 집단 이 그렇지 않은 집단보다 피임지식이 높게 나타났다. 비 록 지식과 태도라는 차이가 있으나 가정에서 피임교육을 받은 집단이 받지 않은 집단에 비해 피임태도가 긍정적 인 것으로 나타난 것은 매우 의미있는 결과라 생각한다. 가정에서 자녀에게 피임 에 관한 내용을 언급한다는 것 
은 매우 어려운 일이라 할 수 있다. 미국 남동부 지역의 대학생들과 대학원생들을 대상으로 한 연구에 따르면 $67 \%$ 의 대상자들이 성교육에 있어 부모가 도움이 되기는 하나 부모를 성교육의 일차적인 자원으로 생각하는 학생 은 $15 \%$ 에 불과하였다[20]. 특히 피임에 관한 내용은 매 우 사적이고 내밀한 것인 만큼 가정에서 자녀와 피임을 논하는 것은 쉬운 일이 아닐 것이다. 그러나 가정에서 피 임교육이 이루어졌던 집단이 그렇지 않은 집단에 비해 피임태도가 긍정적임을 볼 때, 가정내 성교육이 학생들에 게 피임태도를 긍정적으로 정립하는 데 도움이 될 것이 라 생각한다. 아쉽게도 학교에서 피임교육을 받은 경험이 있는 집단과 그렇지 않은 집단 간에는 피임지식에 있어 유의한 차이가 나타나지 않았는데, 이는 현행 성교육이 지루하고 피상적인 내용으로 진행되고 있음을 보여주는 단적인 결과라 하겠다. 고등학교 보건교사들을 대상으로 한 강희선[21]의 연구에 따르면 응급피임약에 대한 교육 을 실시하고 있는 기관은 $53.7 \%$ 였으며 응급피임약에 대 한 교육을 하는데 있어서 주요 장애요인 중 하나로 학교 의 보수적인 시각, 학부모님들의 반대 등을 꼽았다. 즉, 현행 성교육이 현실과 동떨어진 내용으로 구성되어 있어 실질적인 정보를 원하는 학생들의 흥미와 관심을 유발하 지 못한 데에서 비롯된 결과[15]라는 것이다. 이성과의 성행위 경험에 따른 피임태도의 차이를 살펴본 결과, 이 성과 포옹, 키스, 애무 경험이 있는 집단이 그렇지 않은 집단에 비해 피임태도가 긍정적인 것으로 나타났다. 이는 이성과 다양한 성행위 경험이 있는 집단의 경우 원치 않 은 임신이라는 결과를 초래할 가능성이 높으므로 이를 예방하는 수단으로서 피임을 좀더 긍정적으로 인식하여 나타난 결과로 사료된다.

대상자의 피임지식과 태도 간에는 피임지식이 높을수 록 피임태도가 긍정적인 것으로 나타났다. 이는 대학생의 경구 피임약에 관한 지식과 태도를 조사하여 경구피임약 에 대한 지식과 태도 간에 유의한 상관관계가 있음을 보 고한 임현자와 조유향[14]의 결과를 지지하고 있다. 그러 나 피임지식과 피임태도 간에 상관관계가 없다고 보고한 허명행 등[15]의 연구결과와는 차이가 있었다. 간호과 학 생들은 재학기간 동안 타 전공자들에 비해 피임지식을 자주 접하게 되므로 피임지식의 향상과 더불어 피임태도 가 좀더 긍정적으로 형성되었을 가능성이 높다고 생각한 다. 피임지식에 영향을 미치는 변인은 학년, 혼전동거에 대한 의견, 성적, 애무경험이었고 이 변수들의 설명력은 $22.5 \%$ 이었다. 따라서 학년별로 성적수준을 고려하여 피 임지식을 지도해 나가는 것도 필요하다고 생각한다. 황신 우와 정재원[10], Wang 등[6]은 피임실천행위와 임신에 관련된 요인으로 피임 자기효능감을 들었다. 피임 자기효
능감을 증진시키기 위해서는 학생들로 하여금 피임에 관 한 지식을 많이 갖게 하는 것도 중요하지만 피임을 제대 로 실천할 수 있도록 의미있는 주변 사람들의 지속적인 조언도 중요하다고 생각한다. 즉, 간호과 학생들에게 수 업을 통한 피임지식의 전달도 매우 의미가 있지만 이와 더불어 학생상담시 지도교수가 성적이 부진한 여학생들 을 대상으로 그들의 혼전성관계나 동거여부 등을 파악하 여 상황에 적합한 피임법을 제시해주는 것도 중요하다고 생각한다. 또한 피임태도에 영항을 미치는 변인으로서 포 옹경험과 가정에서의 성교육 유무가 있었으며 이 변인들 의 설명력은 $4.3 \%$ 이었다. 피임태도에 대한 예측변인의 설명력이 매우 낮았으나 성교육을 받은 신세대 부모들이 늘어나고 있는 만큼 자녀들에게 좀더 구체적이고 실제적 인 피임방법을 교육하므로써 학생들의 피임태도를 좀더 긍정적인 방향으로 이끌어나가야 할 것이다.

앞으로 사회에 나아가 건강교육자로서의 역할을 담당 하게 될 간호과 학생들에게 교과목 내에 포함된 피임관 련 지식을 보다 체계적으로 전달하고 피임에 대한 긍정 적인 태도를 형성할 수 있도록 지도하므로써 간호과 학 생들 모두가 피임에 대한 정확한 지식과 바람직한 태도 를 보급하는데 중요한 인적자원으로 활동할 수 있어야 할 것이다.

\section{5. 결론 및 제언}

본 연구는 일개 전문대학 간호과 여학생들의 피임지식 과 태도를 살펴보고 이 두 변수 간의 상관관계를 파악하 기 위하여 시도되었다. 대상자는 충청도에 위치한 일개 전문대학 간호과 여학생들 254 명이었고 연구기간은 2011 년 10 월 17 일부터 11 월 11 일까지였다. 대상자의 피임지 식은 일반적 특성에 있어 2학년, 성적이 상위인 집단, 혼 전성교에 찬성하는 집단, 혼전동거에 찬성하는 집단이 그 렇지 않은 집단에 비해 피임지식이 유의하게 높았다. 또 한 성행위 경험에 있어서는 이성과 포옹, 키스, 애무 경험 이 있는 집단이 경험이 없는 집단에 비해 피임지식이 유 의하게 높았다. 피임태도는 일반적 특성에 있어 가정에서 피임교육을 받은 집단이 그렇지 않은 집단에 비해 긍정 적인 태도를 보였고 성행위 경험에 있어 이성과 포옹, 키 스, 애무 경험이 있는 집단이 없는 집단에 비해 긍정적인 태도를 보였다. 대상자의 피임지식과 태도는 정 상관관계 를 보여 피임지식이 높을수록 피임태도가 긍정적인 것으 로 나타났다. 피임지식에 영향을 미치는 변인으로는 학 년, 혼전동거에 대한 의견, 성적, 애무경험이었으며 피임 지식에 대한 이들 변인의 설명력은 $22.5 \%$ 이었다. 피임태 
도에 영항을 미치는 변인으로는 포옹경험과 가정에서의 성교육 유무였으며 피임태도에 대한 이 변인들의 설명력 은 $4.3 \%$ 이었다.

본 연구를 통해 다음과 같이 제언하고자 한다. 본 연구 에서 소수인 이유로 제외되었던 간호과 남학생들을 비롯 하여 일 전문대학에 국한된 본 연구의 한계점을 극복하 는 의미에서 좀더 광범위한 지역의 간호대학생들을 대상 으로 피임지식과 태도에 영향을 미치는 다양한 요인을 규명하기 위한 후속 연구가 진행되기를 바란다.

\section{References}

[1] J. H. Choi, K. E. Kim, and M. A. Shin, "Contraceptive knowledge, contraceptive attitude, and contraceptive use among college students: function of gender, age, and residence", Korean Journal of Human Ecology, Vol. 19, No. 3, pp. 511-512, 2010.

[2] G. Y. Kim, H. B. No, S. H. Park, M. H. Yoo, Y. R. Jung, Y. H. Cho, and Y. A. Choi, "Study on the knowledge, barrier level, and application aspect on contraception of university students", Journal of Ehwa Nursing, Vol. 41, pp. 55-71, 2007.

[3] H. J. Lee, and H. S. Kang, "Rates and methods of contraception among Korean adolescents from 2007 to 2009", Korean Journal of Women Health Nursing, Vol. 17, No. 2, pp. 148-156, 2011.

[4] S. Campo, N. M. Askelson, E. L. Spies, and M. Losch, "Preventing unintended pregnancies and improving contraceptive use among young adult women in a rural, midwestern state: health promotion implications", Women \& Health, Vol. 50, No. 3, pp. 279-296, 2010.

[5] K. Dinas, V. Ahiropoulos, G. Mavromatidis, E. Chatzipantelis, L. Zepiridis, T. Theodoridis, et al., "Current contraceptive awareness and use in greek dental school students", Journal of Women's Health, Vol. 18, No.3, pp. 387-391, 2009.

[6] R. H. Wang, H. H. Wang, and M. T. Hsu, "Factors associated with adolescent pregnancy-a sample of Taiwanese female adolescents", Public Health Nursing, Vol. 20, No. 1, pp.33-41, 2003.

[7] J. E. Song, and H. J. Chae, "Knowledge and educational need about contraceptive according to sex in college students", Korean Journal of Women Health Nursing, Vol. 16, No. 4, pp. 399-408, 2010.

[8] H. S. Kang, "Development of a scale for attitude toward emergency contraceptive pills's use", Journal of the
Korean Data Analysis Society, Vol. 9, No. 3, pp. 1153-1163, 2007.

[9] J. Y. Cho, S. W. Han, and M. S. Song, "Personality-based contraception behavior of female college students". Korean Journal of Women Health Nursing, Vol. 12, No. 4, pp. 338-347, 2006.

[10] S. W. Hwang, and C. W. Chung, "Contraception behavior and related factors in unmarried female and male", Korean Journal of Women Health Nursing, Vol. 17, No. 1, pp. 77-87, 2011.

[11] H. S. Kang, "Emergency contraceptive pills: knowledge, attitude, and intention of high school girls in Korea", Korean Journal of Women Health Nursing, Vol. 15, No. 4, pp. 336-343, 2009.

[12] I. S. Lee, and J. Y. Cho, "Comparative study on the contraceptive knowledge and self-efficacy according to the career tract of high school female students", Journal of the Korean Data Analysis Society, Vol. 21, No. 2, pp. 1-14, 2008.

[13] J. Y. Cho, and I. S. Lee, "Sexual behavior, knowledge, self-efficacy and perceived risk on contraception of male high school students", Journal of the Korean Data Analysis Society, Vol. 12, No. 6, pp. 3179-3192, 2010.

[14] H. J. Lim, and Y. H. Cho, "A study on knowledge and attitude about oral contraceptives in university students", Journal of Korean Academy of Public Health Nursing, Vol. 16, No. 2, pp. 412-422, 2002.

[15] M. H. Hur, H. Y. Ann, E. A. Kwak, K. M. Kim, J. Y. Park, and J. I. R. Lee, "A study on sexual behavior, and correlation between knowledge of contraception and attitude of contraception among university students", Journal of Korean Academy of Nursing, Vol. 37, No. 3, pp. 267-275, 2007.

[16] M. J. Kim, "Structual euation model explaining contraception behaviors of married Korean women", Korean Journal of Women Health Nursing, Vol. 7, No. 2, pp. 141-156, 2001.

[17] M. J. Kim, and H. S. Kang, "A comparative study of consistent and inconsistant contraceptive users on partner communication, perceived contraceptive control, and sexual autonomy", Journal of Korean Academy of Nursing, Vol. 33, No. 6, pp. 784-791, 2003.

[18] F. Faul, E. Erdfelder, A. G. Lang and A. Buchner, G*Power3: A flexible statistical power analysis program for the social, behavioral, and biomedical sciences, Behavior Research Methods, Vol. 39, pp. 175-191, 2007.

[19] S. V. Von, C. K. Kovar, C. Brown, and M. 
Armbruster, "The need for sexual health information: perceptions and desires of young adults", American Journal of Maternity \& Child Nursing, Vol. 31, No 6, pp. 373-380, 2006.

[20] E. R. Scott, C. S. Darcy, C. Jill, and K.. Michael, "Information about human sexuality : source, satisfaction, and perceived knowledge among college students", Sex Education, Vol. 11, No. 4, pp. 471-487, 2011.

[21] H. S. Kang, "Knowledge and attitude toward emergency contraceptive pills of high school health teachers in Korea", Journal of the Korean Data Analysis Society, Vol. 10, No. 2B, pp. 713-725, 2008.

\section{이 인 숙(Inn-Sook Lee)}

[정회원]

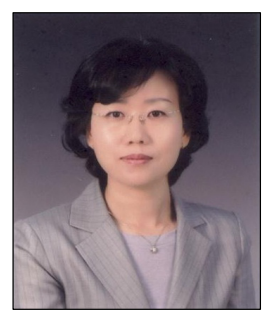

- 1990년 2월 : 가톨릭대학교 의과 대학 간호학 학사

- 1994년 8월 : 연세대학교 보건대 학원 보건간호학 석사

- 2001년 8월 : 가톨릭대학교 대학 원 간호학 박사

- 1990년 3월 1991년 6월 : 가 톨릭대학교 성모병원 신경외과 중환자실 간호사

- 1991년 7월 1997년 2월 : 한성대학교 건강관리실 간호사

- 1998년 3월 현재 : 강동대학교 간호과 교수

<관심분야>

지역사회간호, 학교보건, 보완대체간호

\section{조 아 영(A-Young Cho)}

[정회원]

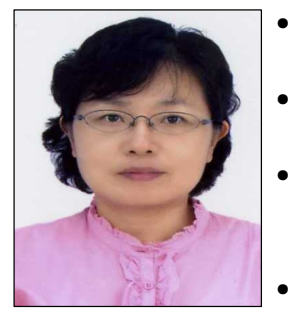

- 1989년 2월 : 가톨릭대학교 의과 대학 간호학 학사

- 2005년 8월 : 가톨릭대학교 임상 간호대학원 간호학 석사

- 1989년 3월 1993년 12월 : 가 톨릭대학교 강남성모병원 신경 외과 중환자실 간호사

- 2002년 6월 2009년 5월 : 보 바스기념병원 수간호사

- 2009년 6월 현재 : 헤리티지너싱홈 간호부장

<관심분야>

노인간호 